\begin{abstract}
Endalew Gemechu Sendo*
Addis Ababa University, College of Health Science, School of Nursing and Midwifery, Addis Ababa, Ethiopia, P.O.Box 1176, Ethiopia

Dates: Received: 25 March, 2014; Accepted: 19 April, 2014; Published: 21 April, 2014

*Corresponding author: Endalew Gemechu Sendo, Addis Ababa University, College of Health Science, School of Nursing and Midwifery, Addis Ababa, Ethiopia, P.O.Box 1176, Ethiopia, E-mail: endalewaau2012@gmail.com www.peertechz.com

ISSN: 2455-3786
\end{abstract}

Keywords: Post exposure prophylaxis, Human Immunodeficiency virus, nursing/midwife students, Hawassa University, Ethiopia
Research Article

\section{Assessment of Level of Knowledge and Practice of Nursing and Midwifery Students on HIV Post Exposure Prophylaxis in Hawassa University, Ethiopia}

\section{Abstract}

Background: Nurses, midwives and other health care workers are at risk from Human Immunodeficiency Virus (HIV) and other blood borne infections in the workplace. Post exposure prophylaxis of HIV is the only way to reduce risk of HIV after potential exposure to needle pricks, blood and body fluids.

Objectives: The objective of this study is to assess the level of knowledge and practice of nursing and midwifery students regarding post exposure prophylaxis for HIV in Hawassa University, College of Medicine and Health Science in Ethiopia.

Methods: Institution- based cross-sectional descriptive study was conducted from October to December 2013. A total of 185 students (comprising of 136 nursing and 49 midwifery) who were eligible for the survey were involved in the study. Data was collected using pretested self-administered questionnaires. Data was entered and analyzed by Statistical package for Social Science (SPSS) version 20. Associations of selected variables with HIV PEP use were assessed using chi-square test. A p-value of $<0.05$ has been considered as statistically significant. The results were presented in frequency tables and percentages.

Results: A total of all 185 students belonging to $2^{\text {rd }}, 3^{\text {rd }}$ and $4^{\text {th }}$ years of nursing / midwifery students participated in the survey. The mean age of respondents was 21.04 \pm 1.59 years.

Among all of the respondents, 54 (29.2) were exposed to HIV risky conditions and of these exposed respondents, the most $32(59.3 \%)$ started PEP. The main reasons reported as a cause of exposure to HIV risk conditions in the work place were; lack of protective barriers $43(79.7 \%)$ followed by lack of knowledge on standard precautions 10 $(18.5 \%)$. Students of final year were more likely to Practice PEP $(p=0.01)$ as compared to students studying in $2^{\text {nd }}$ year and $3^{\text {rd }}$ year. However, post exposure prophylaxis use was not associated with gender and professional category $(P>0.05)$

Conclusion and Recommendations: The present study revealed that the level of knowledge and practice of Nursing and midwifery students regarding post-exposure prophylaxis against HIV was inadequate. Accessible PEP centre with proper guideline is recommended so that their practice towards utilization of PEP can be enhanced.

\section{Background}

HIV/AIDS is a serious public health problem costing the lives of many people including health care workers and health science students [1]. It is probably the most serious and causes the highest level of anxiety amongst health care workers (HCWs) and students in many countries [2]. Each day thousands of healthcare workers (HCWs) around the world suffer accidental occupational exposures to blood borne pathogens $[3,4]$.
The World Health Organization (WHO) estimates that 3 million percutaneous occupational exposures to blood or other body fluids occur in health care settings. CDC estimates 380,000 needle stick injuries in US hospital yearly. Globally 98 confirmed and 194 possible cases of HCWs infected of HIV occupationally. Ninety percent of occupational exposure across the world occurred in developing countries [4]. In developing countries like Ghana, Indonesia and Uganda, $80-90 \%$ of patients who visited a health centre received one or more injections per visit [5]. A positive correlation has been 
reported between the frequency of injections and the prevalence of blood-borne infections in the population. In South Africa, 91\% of junior doctors reported sustaining a needle stick injuries [NSI] in the previous year [6] In Ethiopia, there are 800,000 people living with HIV/AIDS and 1.5\% of population aged 15-49 is infected with HIV [10]. However, there is no national study concerning risks of accidental blood exposure and PEP use in Health care workers in Ethiopia.

Post exposure prophylaxis (PEP) prevents $81 \%$ of sero conversion [1]. The estimated risk of HIV transmission is $0.3 \%$ after a needle stick injury and $0.09 \%$ after a mucous-membrane exposure $[1,5]$. Nurses and midwives are probably the most vulnerable of all the health care workers to get exposed to the occupational hazard of HIV infection. In developing countries, the risk of occupational transmission of blood-borne pathogens is increased by excessive handling of contaminated needles that result from unsafe practices like administration of unnecessary injections on demand, the reuse of non-sterile needles, capping needles, and the unregulated disposal of hazardous waste $[5,6]$.

These are largely preventable through strict infection control, universal precautions, use of safe devices, proper waste disposal and prompt management of exposures including the use of post-exposure prophylaxis for HIV [7]. Post exposure prophylaxis is currently the only way to reduce the risk of HIV infection in someone exposed to the virus. It refers to the use of antiretroviral medications to help prevent HIV transmission. The rationale is that ARVs given immediately after exposure can stop the virus from disseminating in the body and establishing infection. The majority of occupational exposures do not lead to HIV infection [6].

Preventing the occurrence of HIV infection resulting from such accidental injuries at work place and the use of HIV Post-exposure prophylaxis (PEP) is recommended by WHO/ILO $[1,9]$. With regard to this, the Federal Ministry of Health of Ethiopia developed guidelines for infection prevention and PEP use (in the ART guideline) in 2004 and 2005, respectively $[7,8]$.

Nurses are an integral part of the healthcare system and are perceived to be knowledgeable in providing institutional and community health care to the patients $[10,11]$. They play an important role in providing healthcare to patients, especially in rural areas of the country as there is less number of doctors. The role of nurses is even becomes more critical in a society that is battling to control and prevent HIV/ AIDS infection and related super infections [12,14].

According to the World Health Organization, the exact scale of occupational risk in the health sector is unclear, partly because of the stigma and blame attached to the reporting of sharps injuries and the lack of available post-exposure prophylaxis [4,5]. Nursing students are also at risk of such infections and injuries due to accidental contamination during their practical occupational exposure.

Nurses are usually at the forefront of patient care [13]. So when they are students they need to have an adequate knowledge and a positive attitude towards healthcare problems including HIV/ AIDS which has recently become a major public health concern in the country $[15,16]$. In contrary to their roles, studies from different countries have reported a poor knowledge among the nurses regarding HIV/AIDS [17].

However, at a national level the number of health professionals and students that suffer from sharp injuries remains unknown in Ethiopia. Thus, identifying the knowledge of nursing students may provide baseline data which may then be a useful source for intervention. Providing pertinent information on PEP for the health care professionals including students would help to prevent the transmission of HIV, provide epidemiological data, identify unsafe practices, and reduce anxiety, and/or productivity.

This study, therefore, assessed the level of knowledge and practice of nursing and midwifery students on HIV post exposure prophylaxis in Hawassa Univesrsity, College of Medicine and Health Sciences in Ethiopia.

Hawassa University [HU] is $275 \mathrm{~km}$ away from Addis Ababa to the South of Ethiopia. It was established at heart of Hawassa City in April 2000. Since 1976, the different colleges of HU had been operational starting with the College of Agriculture. Today, HU is a comprehensive university engaged in the provision of all-round education, research, training, and community service through its diversified areas of academic programs. Currently, the university has an undergraduate student population of 22,000 consisting of 18,203 males (82.7\%) and 3797 females (17.3\%). Most of the students come from the rural areas of Ethiopia.

\section{Methods}

\section{Study design, sample size and sampling technique}

Institution- based cross-sectional descriptive study was conducted from October to December 2013. The study participants were all regular undergraduate nursing/midwives students of Hawassa University who registered for the academic year of 2013. Census sampling method was used. All second year and above nursing/midwives students were eligible to participate in the study. However, students of pre-clinical years (1st year) were excluded from the survey. A total of 185 students (comprising of 136 nursing and 49 midwifery) who were eligible for the survey were involved in the study

\section{Data collection}

Data was collected using pretested self-administered questionnaires. The questionnaire was adopted from reviewed literatures $[2,3]$. The questionnaire was translated into the Amharic (local language) by linguistic professionals. The respondents were approached in their respective departments and after taking an informed verbal consent, the questionnaires were distributed. Then the completely filled questionnaires were collected on the same day

\section{Data analysis}

Data was entered and analyzed by Statistical package for Social Science (SPSS) version 20. In descriptive analysis, the mean and standard deviation of continuous variables and percentages of categorical variables were computed. Associations of selected variables with HIV PEP use were assessed using chi-square test. A 
p-value of $<0.05$ has been considered as statistically significant. The results were presented in frequency tables and percentages

\section{Ethical consideration}

The ethical clearance was obtained from the institutional review board of Hawassa University. All study participants were adequately informed about the purpose, method and anticipated benefit of the study by the data collectors. They were given clear options regarding voluntary participation. Verbal consent was obtained from each participant and confidentiality of the study subjects was maintained.

\section{Operational definitions and terms used in this study:}

Adequate Knowledge- when respondents correctly answer $>75$ $\%$ of the seven knowledge questions.

Inadequate knowledge- when the correct answer of respondents is $<75 \%$ of the seven knowledge questions.

Post-exposure prophylaxis (PEP) is short term antiretroviral treatment given to reduce the likelihood of HIV infection after potential exposure occupationally.

PEP use /practice- reported as respondents have practiced using Post-exposure prophylaxis of HIV following occupational exposure to HIV risky conditions.
HIV risky conditions- when they are exposed to occupational hazards through per cutaneous injury such as needle stick or cut with sharps, contact with the mucus membrane of eyes or mouth of HIV infected person, contact with non intact skin exposed with blood or other potentially infectious body fluids in the workplace.

\section{Results}

\section{Socio demographic characteristics}

A total of all 185 students belonging to $2^{\text {rd }}, 3^{\text {rd }}$ and $4^{\text {th }}$ years of nursing /midwifery students participated in the survey. Therefore, the response rate in our study was $100 \%$. One hundred thirty Six students (73.5\%) were from nursing and while 49 students $(26.5 \%)$ were from midwifery categories. Ninety seven (52.4\%) were female while eighty eight (47.6\%) students were male. The mean age of respondents was $21.04 \pm 1.59$ years. Majority $105(56.7 \%)$ were Christians. Regarding the marital status of the respondents, most 181 $(97.8 \%)$ of them were single.

\section{Respondents' Knowledge of HIV post exposure prophylaxis}

Respondents' knowledge of post exposure prophylaxis is as presented in Table 1 below. When asked to state if they were familiar with the concept of post exposure prophylaxis, the most 124 (67.1\%)

Table 1: Respondents' knowledge of PEP, Hawassa University, December 2013.

\begin{tabular}{|c|c|c|c|}
\hline Characteristics & & & Total (\%) \\
\hline 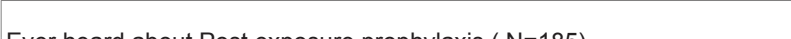 & Profess & jory & \\
\hline & Nurses & Midwives & \\
\hline $\begin{array}{l}\text { Yes } \\
\text { No }\end{array}$ & $\begin{array}{l}91(49.2) \\
45(24.3)\end{array}$ & $\begin{array}{c}33(17.8) \\
16(8.6)\end{array}$ & $\begin{array}{c}124(67.1) \\
61(32.9)\end{array}$ \\
\hline $\begin{array}{l}\text { From where did you get the PEP information }(\mathrm{N}=124)^{\star *} \\
\text { - Class rooms lecture } \\
\text { - Personal studies } \\
\text { - Seminars } \\
\text { - Posters }\end{array}$ & $\begin{array}{c}53(42.7) \\
18(14.5) \\
15(12.1) \\
5(4.0)\end{array}$ & $\begin{array}{l}23(18.6) \\
4(3.2) \\
4(3.2) \\
2(1.6)\end{array}$ & $\begin{array}{c}76(61.3) \\
22(17.7) \\
19(15.4) \\
7(5.6)\end{array}$ \\
\hline $\begin{array}{l}\text { High risk body fluids }(\mathrm{N}=124)^{* *} \\
\text { - Vaginal discharge } \\
\text { - Semen } \\
\text { - Blood } \\
\text { - Perebrospinal fluid } \\
\text { - Others }\end{array}$ & $\begin{array}{l}47(25.4) \\
57(30.8) \\
78(42.2) \\
63(34.1) \\
40(21.6 \\
0(0)\end{array}$ & $\begin{array}{c}37(20) \\
63(34) \\
40(21.6) \\
58(31.3) \\
35(18.9) \\
0(0)\end{array}$ & $\begin{array}{c}84(45.4) \\
120(64.8) \\
118(63.8) \\
121(65.4) \\
75(40.5) \\
4(2.1)\end{array}$ \\
\hline $\begin{array}{l}\text { The time to start taking PEP for HIV }(\mathrm{N}=124) \\
\text { - Within one hour } \\
\text { - After } 6 \text { hrs of exposure } \\
\text { - After } 12 \mathrm{hrs} \text { of exposure } \\
\text { - After } 72 \mathrm{hrs} \text { of exposure }\end{array}$ & $\begin{array}{l}39(31.5) \\
17(13.7) \\
21(16.9) \\
14(11.3)\end{array}$ & $\begin{array}{l}21(16.9) \\
7(5.6) \\
4(3.2) \\
1(0.8)\end{array}$ & $\begin{array}{l}60(48.4) \\
24(19.4) \\
25(20.1) \\
15(12.1)\end{array}$ \\
\hline $\begin{array}{l}\text { Length of time to take PEP for } \mathrm{HIV}(\mathrm{N}=124) \\
\text { - } 28 \text { days } \\
\text { - } 6 \text { days } \\
\text { - Life long } \\
\end{array}$ & $\begin{array}{l}62(50) \\
15(12.1) \\
9(7.3) \\
5(4)\end{array}$ & $\begin{array}{c}26(21) \\
3(2.4) \\
4(3.2) \\
0(0)\end{array}$ & $\begin{array}{c}88(71) \\
18(14.5) \\
13(10.5) \\
5(4.0)\end{array}$ \\
\hline $\begin{array}{l}\text { Do you know about the PEP guideline? }(\mathrm{N}=124) \\
\text { Yes } \\
\text { No } \\
\text { Don't know }\end{array}$ & $\begin{array}{c}65(52.4) \\
19(15.3) \\
7(5.6)\end{array}$ & $\begin{array}{l}23(8.6) \\
7(5.6) \\
3(2.4)\end{array}$ & $\begin{array}{l}88(71) \\
26(21) \\
10(8.0)\end{array}$ \\
\hline
\end{tabular}

${ }^{* *}$ Multiple responses 
of the 185 students consisting of $91(49.2 \%)$ nursing, and midwives $33(17.8 \%)$ reported that they had ever heard about it.

With regards to the source of information about PEP, out of 124 respondents who ever heard about PEP, most of the students responded that it was taught as a part of the curriculum (61.3\%). Other important sources of information mentioned by the students included personal studies (17.7\%), seminars (15.4\%) and posters (5.6\%). One hundred twenty one (65.4\%) respondents correctly answered that cerebrospinal fluid is considered as high risk body fluids for transmission of HIV, followed by semen 120(64.8\%), blood $118(63.8 \%)$ and vaginal discharge $84(45.4 \%)$ respectively. Only 60(48.4\%) respondents knew that PEP initiation is best within 2 hours of needle prick injuries and $88(71 \%)$ knew that PEP is given for 28 days.

Twenty six (21\%) of the respondents reported that they don't know PEP guidelines. Eighty six (46.5\%) of nurses and 46(24.9\%) of midwives answered correctly that PEP is indicated for person who is exposed to HIV risk by needle sticks or cuts, followed by person who is exposed to HIV with blood or body fluids in eyes and mouth 55(29.7\%) nurses versus $84(45.4 \%)$ midwives and person who is exposed to HIV with blood or body fluids in broken skin only $24.2 \%$ nurses versus $30.8 \%$ midwives.

Respondents' level of knowledge was measured by calculating the total possible score in PEP of HIV questions \& classified into 2 categories: Adequate knowledge (above 75 percentile), and inadequate knowledge (below 75 percentile). The majority (63\%) of the respondents had inadequate knowledge on PEP of HIV.

Respondents' exposure to HIV risk conditions and practice of PEP

Respondents' exposure to HIV risk conditions and practice of PEP was shown in Table 2. Among all of the respondents, 54 (29.2) were exposed to HIV risky conditions and of these exposed respondents, $32(59.3 \%)$ took PEP. However, 22 (40.7\%) of the exposed respondent did not take PEP. Also worth mentioning is the fact that even out of those 32 respondents that agreed to use PEP, only 24 respondents completed the recommended duration for the use of PEP.

Among the respondents who ever exposed to HIV risky conditions, 28 (51.9\%) of the respondents have sustained needle stick injury during their clinical practice, 18 (33.3\%) exposed to blood and $8(14.8 \%)$ exposed to body fluids. The main reasons reported as a cause of exposure to HIV risk conditions in the work place were; lack of protective barriers $43(79.7 \%)$ followed by lack of knowledge on standard precautions $10(18.5 \%)$. Of the 22 participants who didn't initiate PEP, the major reasons reported for not using PEP of HIV after exposure were lack of awareness of the existence of PEP service/ protocols by 19 (86.4\%), worried about side effect of drugs by 10 (45.5\%), lack of support and encouragement to report by $8(36.4 \%)$, and the patient was at low risk for HIV by $4(18.2 \%)$.

Table 3 details the association between selected variables and HIV PEP Practice. Using Chi square test, the year of study emerged as an independent predictor for receiving PEP for HIV. Students of final year were more likely to Practice PEP $(\mathrm{p}=0.01)$ as compared to students studying in $2^{\text {nd }}$ year and $3^{\text {rd }}$ year. However, post exposure prophylaxis use was not associated with gender and professional category $(\mathrm{P}>0.05)$.

\section{Discussion}

This study assessed the level of knowledge and practice of nursing and midwifery students on HIV post exposure prophylaxis in Hawassa Univesrsity, College of Medicine and Health Sciences in Ethiopia.

Table 2: Respondents' exposure to HIV risky conditions and Practice of PEP, Hawassa University, December 2013.

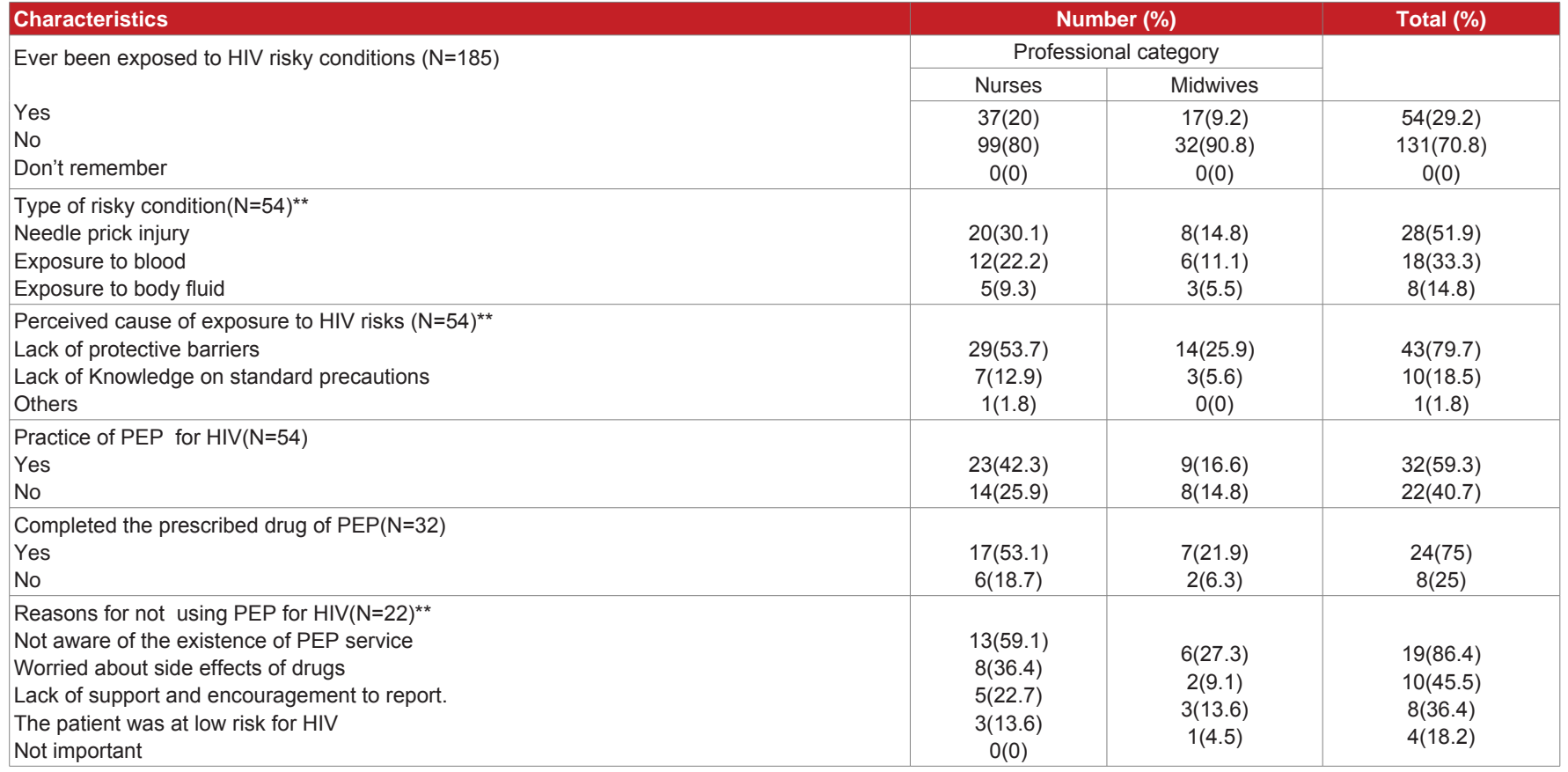

** Multiple responses 
Table 3: Factors associated with HIV PEP Practice.

\begin{tabular}{|c|c|c|c|c|}
\hline \multirow[t]{2}{*}{ Variables } & \multicolumn{3}{|c|}{ Ever used PEP(N=54) } & \multirow[t]{2}{*}{$\mathrm{X}^{2}$ (P-Value) } \\
\hline & Yes & No & Total (\%) & \\
\hline $\begin{array}{l}\text { Sex: } \\
\text { Male } \\
\text { Female }\end{array}$ & $\begin{array}{l}14 \\
18\end{array}$ & $\begin{array}{l}11 \\
11\end{array}$ & $\begin{array}{l}25(46.3) \\
29(53.7)\end{array}$ & $4.579(0.862)$ \\
\hline $\begin{array}{l}\text { Profession: } \\
\text { Nursing students } \\
\text { Midwife students }\end{array}$ & $\begin{array}{c}23 \\
9\end{array}$ & $\begin{array}{c}14 \\
8\end{array}$ & $\begin{array}{l}37(68.5) \\
17(31.5)\end{array}$ & $3.791(0.561)$ \\
\hline $\begin{array}{l}\text { Level of study: } \\
2^{\text {nd }} \text { year } \\
3^{\text {rd }} \text { year } \\
4^{\text {th }} \text { year }\end{array}$ & $\begin{array}{c}2 \\
11 \\
19\end{array}$ & $\begin{array}{c}13 \\
7 \\
2\end{array}$ & $\begin{array}{l}15(27.8) \\
18(33.3) \\
21(38.9)\end{array}$ & $7.432(0.001)$ \\
\hline
\end{tabular}

Health care workers and students on training who are directly involved in treating and nursing patients face a great risk of acquiring blood-borne infections from the workplace [19]. In health care settings there is an increased risk of HIV transmission to HCWs because of occupational exposure to blood borne infection from needle sticks [20]. Evidence suggests that treatment with antiretroviral drugs soon after occupational exposure to HIV decreases the risk of infection.

Typically regimens are prescribed for a four week period; PEP should be started within hours of the potential exposure not days. The sooner PEP is started the better, and it should be started within the first 72 hours after exposure [21].

In the present study, among all study participants $67.1 \%$ have heard about PEP for HIV. This finding is lower compared to other study which was conducted in a tertiary hospital in Nigeria (97\%) and Gonder in Ethiopia (92.8\%) [15,16], respectively. Considerably high proportions $(63 \%)$ of nursing and midwifery students were knowledgeable about PEP of HIV in this study area. The findings of this study are higher than the results of the study done in Malaysia Hospital where $56 \%$ of nurses and $25 \%$ of midwives were aware of correct risk of transmission of HIV at work place $[1,17]$

The proportion of respondents who heard about PEP of HIV from formal class room lectures was $61.3 \%$. In this study, it was evident that the theoretical aspects of training of trainees emphasized the importance of incorporating the concept of PEP into classroom activities as the majority of the respondents claimed to have the information about PEP during their classroom sessions. However, some students seemed to be making use of the opportunity for personal studies through the reading of books and journals to make up for whatever deficiency they had in the class as a total of $17.7 \%$ got information about the concept of PEP from the literature.

However, the role played by display of posters and similar IEC materials was extremely low among the respondents (5.6\%). Generally, the posting of such materials on strategic locations within the hospital and class rooms was very limited to only a few places.

Considering the importance of such materials in reminding, warning and informing health Science students as regards what they need to know and/or do, it could be more helpful if information is provided on visual aid within each ward or unit and other strategically located places within the hospital or college vicinity.

In the present study, $65.4 \%$ of respondents had knowledge that high risk body fluids for transmission of HIV are cerebrospinal fluid followed by semen (64.8\%), blood (63.8\%), and peritoneal fluid (40.5\%), respectively. This finding is supported by a study of Foster,Lee, Mcgaw \& Frankson which showed that, participants considered the following fluids high risk for HIV transmission: CSF (55\%), peritoneal fluid (53\%) breast milk (79\%), saliva (14\%), urine (27\%), pleural fluid (53\%), synovial fluid (37\%), feces $(27 \%)$, and vomitus (21\%) [18].

In this study, almost half (48.4\%) of respondents had knowledge that the best time for initiation of PEP is within 2 hours of exposure. This finding is almost similar with a study of Alenyo, Fualal \& Jombwe which showed that $51.8 \%$ of respondents' had knowledge about best time for initiation of PEP $[18,19]$. However, the current findings is higher than the finding from study conducted in Mulago Hospital in Uganda which showed only $22.3 \%$ being sure it should be started within an hour of exposure [11]. The difference might be because of the difference on the level of awareness among the different study populations.

Regarding respondents' exposure to HIV risk condition \& practice of PEP, only $29.2 \%$ of respondents reported that they had exposed to HIV risk condition in their work place. Among 54 respondents exposed to HIV risk conditions, $51.9 \%$ of them sustained needle prick injury, $33.3 \%$ of them exposed to blood and $14.8 \%$ of them exposed to body fluids. This finding is supported by a study of Bosena et al. $[1,18]$ which showed that out of 174 who were exposed to risk of HIV, $60.3 \%$ sustained needle prick/cut by sharps, $44.3 \%$ to blood and $39.1 \%$ exposed to patients' body fluid. This study showed that large number of students reported as they have ever been exposed to HIV risk conditions which is higher than the 2003 Italian study that indicated the overall (HIV, HCV, HBV) occupational exposure to be $11.3,11,4.9$, and $4.1 \%$, in midwives, nurses, cleaners, and laboratory technicians, respectively [22].

As regards to respondents' opinions on causes of exposure to HIV risk, $79.7 \%$ of respondents perceived lack of protective barrier followed by lack of knowledge on standard precautions (18.5\%) \& others (1.8\%). This finding is supported by a study of Bosena et al which showed that the perceived causes of exposure were; high workload $44.3 \%$, lack of protective barriers $33.3 \%$ and lack of knowledge on standard precautions $17.8 \%[1,18]$.

Nevertheless, $29.2 \%$ of the exposed respondents who took PEP for HIV in this study, only $75 \%$ of them were able to complete the regimen of the drug which requires 28 days. However, of those exposed, 25\% reported that they did not use PEP. This finding was in agreement with other study conducted in Dares Salaam in which they showed that $40 \%$ of the respondents failed to use PEP for the full length of time prescribed [20].

On the other hand, study conducted in Gujarat showed that their respondents had better practice in this regard than our study participants in which more than $94 \%$ were able to complete the regimen $[21,23]$. This fact alerts that the practice of PEP for HIV in the study area needs improvement. This difference might be due to the difference in the study settings. The difference could also be explained by the fact that our study population included only students, while 
the other studies have included all health care workers and students. Generally, the need to embark on actions aimed at ensuring protection of health personnel including students thus become very apparent so as to limit chances of HIV infection from the workplace.

One strategy to minimize long-term consequences of occupational hazards including needle stick injuries is to improve medical student awareness about occupational health. Assessing the risk of an exposure, management protocols, and understanding the role and risk of anti-retroviral prophylaxis are important concepts to teach.

\section{Conclusion and Recommendations}

The present study revealed that the level of knowledge and practice of Nursing and midwifery students regarding post-exposure prophylaxis against HIV was inadequate.

Prevention of occupational infection with blood-borne pathogens to these young students who are not yet in employment should be a priority to the national program for promotion of infection control. Hence, establishing a system that includes written protocols for prompt reporting of occupational exposure, evaluation, counseling, treatment and follow-up is imperative. Students should have access to clinicians who can provide post exposure care during all working hours, including nights and weekends. Antiretroviral agents for PEP should be readily available for timely administration. . Moreover, formal pre- service training for all students regarding PEP for HIV should be provided to advance their knowledge. Accessible PEP centre with proper guideline is also recommended so that their practice towards utilization of PEP can also be enhanced.

\section{Acknowledgments}

I would like to thank Hawassa University Research and Publication Office for financing this research project. I am indebted to all students who provided me their responses. I also thank data collectors for their support.

\section{References}

1. Tebeje B1, Hailu C (2010) Assessment of HIV Post Exposure Prophylaxis use Among Health Worker of Governmental Health Institutions in Jimma zone, Oromiya Region, Southwest Ethiopia. Ethiop J Health Sci 20: 55-64.

2. Gupta A, Anand S, Sastry J, Krisagar A, Basavaraj A, et al. (2008) High risk for occupational exposure to HIV and utilization of post-exposure prophylaxis in a teaching hospital in Pune, India. BMC Infect Dis 21: 142.

3. Sabane HH, Dixit RR, Durge PM (2011) Impact of Knowledge about Post Exposure Prophylaxis among Nursing Students. Healthline 2: 27-30.

4. Joint United Nations Programme on HIVIAIDS (UNAIDS): World health organization.

5. Sagoe-Moses C, Pearson RD, Perry J, Jagger J (2001) Risks to heath care workers in developing countries. N Engl J Med 345: 538-41.

6. Rabbits JA (2003) Occupational exposure to blood in medical students. S Afr Med J 2003; 93:8.

7. Disease Prevention, Control Department. Infection Prevention. Guidelines for Healthcare facilities in Ethiopia, Addis Ababa, Ethiopia, July 2004.

8. Ministry of Health (2005) Guideline for implementation of Antiretroviral therapy in Ethiopia, Addis Ababa, Ethiopia 15.

9. Ethiopian AIDS resource center. htt://www.etharc.org. Accessed on December 2013.

10. Federal Ministry of health: National HIVIAIDS prevention and control office, AIDS in Ethiopia. Sixth report.

11. (WHO), AIDS epidemic update: December 2006. Geneva: UNAIDS/WHO.

12. Sharma A, Marfatiya YA, Ghiya R (2007) Post-exposure prophylaxis for HIV. Indian J Sex Trans Dis and AIDS 28: 61-68.

13. Khan AZ, Duncan KM, Escofet X, Miles WF (2002) Do we need to improve awareness about HIV post exposure prophylaxis? Ann R Coll Surg Engl 84: 72-73.

14. Whitby M, McLaws ML, Slater K (2008) Needlestick injuries in a major teaching hospital: The worthwhile effect of hospital-wide replacement of conventional hollow-bore needles. American Journal of Infection Control 36: 180-186.

15. Research article summary, 2008 assessing knowledge, attitude and practice on occupational blood exposure, Morocco.

16. Owolabi RS, Alabi P, Ajayi S, Daniel O, Ogundiran A, et al. (2012) Knowledge and Practice of Post Exposure Prophylaxis (PEP) against HIV Infection among Health Care Providers in a Tertiary Hospital in Nigeria. JIAPAC 11: 179-183.

17. Mathewos B, Birhan W, Kinfe S, Boru M, Tiruneh G, et al. (2013) Assessment of knowledge, attitude and practice towards post exposure prophylaxis for HIV among health care workers in Gondar, North West Ethiopia. BMC Public Health 13: 508 .

18. Bairy KL, Ganaraja B, Indira B, Thiyagar N, Choo CM, et al. (2005) Awareness of post-exposure prophylaxis guidelines against occupational exposure to HIV in Hospital Sungai Petani. Med J Malaysia 60: 10-14.

19. Kalpana Sharma Dhakal (2012) Knowledge of Nurses on Post Exposure Prophylaxis of HIV. IJPBA 3: 1394-1399.

20. Alenyo R, Fualal J, Jombwe JJ (2009) Knowledge, Attitude and Practices of Staffs towards Post-exposure Prophylaxis for HIV Infection at Mulago Hospital in Uganda. East and Central African Journal of Surgery 14: 99-102.

21. Chagani MM, Manji KP, Manji MP, Sheriff FG (2011) Healthcare workers' knowledge, attitudes, practices on post exposure prophylaxis for HIV in Dar es Salaam. Tanzania Med J 25:33-38.

22. Shevkani M, Kavina B, Kumar P, Purohit H, Nihalani U, et al. (2011) An overview of post exposure prophylaxis for HIV in health care personals: Gujarat scenario. Indian J Sex Transm Dis 32: 9-13.

23. Bandolier E (2003) Occupational exposure to hospital employees in Italian hospitals over 5.5 years. 